\title{
Delivering Future Clinical Trials in Rheumatology
}

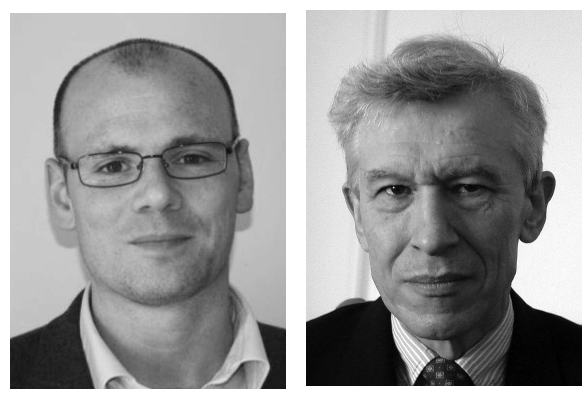

Clinical trials form the cornerstone of evidence-based medicine. Despite their crucial importance, clinicians involved in trials research face major challenges. These are highlighted by Janet Pope and other Canadian experts in this issue of The Journal ${ }^{1}$. The concerns they raise have a Canadian focus but an international relevance. Clinically effective treatments and care pathways rely on clinical trials $^{2}$. Without trials, clinical practice is reduced to anecdotes and expert opinions. Trials are complex, meeting high standards is demanding, and successfully completing trials requires dedication and expertise. As a consequence, involvement of clinical academics is essential.

Experience in England echoes Canadian perspectives. Changes in funding arrangements have made trials run by the pharmaceutical industry today unattractive for clinical academics compared to historical times. There has been an increase in investigator-led trials funded by governmental bodies such as the UK National Institute for Health Research and charities like Arthritis Research UK, but it is difficult to attract sufficient research funding to cover research costs from these sources alone.

Therapeutic innovations driven by large, successful clinical trials have revolutionized rheumatology. One crucial development has been the introduction of biological treatments ${ }^{3}$. That success reflected positive interactions between the pharmaceutical industry and clinical researchers. Examples of other innovations in inflammatory arthritis include focusing on early treatment ${ }^{4}$ and combining disease-modifying drugs ${ }^{5}$. These latter advances reflect investigator-led research in areas of limited commercial interest. This brief list highlights what trials can achieve. It is not in any way comprehensive.

While many innovations in disease management have emerged from recent rheumatology trials, important clinical problems remain to be solved. Here are 3 examples: (1) how to increase the numbers of patients with inflammatory arthritis achieving sustained remissions ${ }^{6}$; (2) how to make biological treatments more cost effective ${ }^{7}$; and (3) how to broaden trial entry criteria, which currently classify as ineligible for trials most patients with inflammatory arthritis seen in routine clinics ${ }^{8}$. Addressing these and other pressing questions requires more trials, not fewer. Reducing the number of rheumatology trials will harm the whole specialist field.

Are the concerns of Canadian clinical trials units, with their substantial trials experience and major contributions to developing treatments for arthritis, justified? Aesop's fable of the boy who cried wolf highlights the risks of premature calls for help and assistance. However, the balance of evidence suggests that clinical trial researchers' current concerns are reasonable. But should the current situation be viewed as a threat or an opportunity? In reality these 2 concepts form 2 sides of the same coin. Each threat is balanced by an opportunity. Albert Einstein has been credited with suggesting that "in the middle of difficulty lies opportunity." Whether the sentiment accurately reflects Einstein's opinions, clinical trial experts ought to view the present situation as a springboard for new initiatives.

The current model for funding clinical trials research represents the historical fusion of several different factors. The pharmaceutical industry needs to develop and evaluate the efficacy and safety of its products. Its trials are highly regulated by national and international agencies. The costs of pharmaceutical innovation mean manufacturers must undertake international trials and take account of both time and costs. The regulatory environment makes them cautious and conservative. They prefer the simplicity of establishing efficacy in placebo-controlled trials that enroll patients with active disease rather than compare new treatments with the best available standard care in the majority of patients.

The inevitable consequence of these drivers is that fewer trials are undertaken in wealthy countries. Placebo-controlled trials in active disease are particularly difficult when most patients receive the best available care and the admin-

See Arthritis clinical trials at a crossroad, page 14 
istrative hurdles facing new trials are maximal. More trials are being undertaken in countries without these limitations. This creates the dilemma of new treatments being mainly investigated in one group of patients but predominantly prescribed in another.

A related and equally critical issue is the universality of findings in clinical trials research. We work in an area of London where great wealth and poverty coexist. Our patients have a wide range of ethnic and cultural backgrounds. There is evidence that differences in ethnicity ${ }^{9}$, deprivation ${ }^{10}$, and health beliefs ${ }^{11}$ have substantial effects on treatment outcomes. They also affect relative toxicity; for example, the risk of tuberculosis with biologic treatments is far higher in some ethnic groups than others ${ }^{12}$. Clinical trials research needs to strike a balance between localism and internationalism. It seems essential for some clinical research to be undertaken locally: marketing treatments without any local evidence for efficacy seems inappropriate. However, caution is needed in finding a balance between local and international research, because international collaboration reduces unnecessary reduplication in clinical trial research.

Many healthcare funders pay for treatments but they commission very little research to consider whether their funding decisions deliver high-quality care and value for the money. Biologic treatments illustrate the limitations of this approach. They can be highly effective, and in many settings, dramatically improve patients' lives. They are also very expensive, with international expenditures counted in the billions of dollars. Pharmaceutical manufacturers, regulators, and medical staff do not usually have prominent roles in funding decisions. It is not one of their key remits to ensure healthcare funders spend money wisely. Consequently there have been few trials designed to test the cost-effectiveness of new, high-cost treatments compared to the best possible standard care in routine clinical practice settings enrolling typical patients attending for specialist care.

Pragmatic trials, conducted within the setting of routine care, the costs of which could be met by healthcare funders, may identify ways of achieving more for less. A small expenditure on research by healthcare funders is therefore likely to increase the cost effectiveness of the services they fund. One answer to the problem of funding clinical trials research in Canada and elsewhere is for healthcare funders to have a remit, or even a responsibility, to fund research on clinical effectiveness.

A final issue is that of oversight of clinical trials. In England and other countries trial oversight has become onerous. Clinical trials research can involve climbing administrative mountains. These difficulties have been extensively described by many experts ${ }^{13,14}$. Government regulations are often associated with delay. Charles Dickens vividly captured this ethos in his description of the Circumlocution Office. Victorian London has vanished, but this echo of the 1850s remains a potential brake on progress.
However, it is also important to recognize that these barriers were developed for good reason. Research misconduct in the delivery and reporting of clinical trials remains a problem ${ }^{15}$. Clearly, a strong governance framework is required. Striking the balance between thorough oversight that ensures good clinical practice and excessive regulation that stifles research is challenging. Janet Pope and colleagues argue that the current balance is wrong. Most experts agree.

Funding clinical research has never been simple. The need for research funding always exceeds the funds available. However, setting high hurdles is likely to ensure the best research is delivered. Funding decisions should have a Darwinian perspective in which only the best ideas survive. While clinical researchers need to fight their corner, they need to fight logically and collaboratively. Canadian clinical trials research in rheumatology has made important historical contributions, is currently performing well, and needs to remain successful. Both Canadian patients and payers need vibrant and active clinical trial units in rheumatology. Similarly, all developed countries need to be involved in clinical trials research.

The challenges faced in Canada will be overcome only through collaboration across the rheumatology sector as a whole. We believe that 3 areas are most likely to be amenable to change. These are ensuring some pharmaceutical funding generates research evidence for efficacy in the populations being treated with their new drugs, that healthcare funders are engaged in developing research evidence for clinical effectiveness, and that the extent of research governance oversight is realistic and affordable. If clinicians and patients work in tandem, clinical trials research in rheumatology will remain a vibrant and successful enterprise able to develop new, effective approaches to the care of arthritis.

Our final thought: Clinical trials are a means to an end, not an end in themselves. We believe it would be easier to gain support for trials in arthritis if our specialty had a few clearly defined longterm goals. Potentially achievable goals of interest to the community at large are most likely to be successful. They could help gain external support to fund more trials in arthritis. An example of such a goal is minimizing disability in people with inflammatory arthritis. There are several other alternative goals.

JAMES B. GALLOWAY, PhD, MRCP, Lecturer and Honorary Consultant Rheumatologist; DAVID L. SCOTT, MD, FRCP,

Professor of Clinical Rheumatology, Academic Department of Rheumatology, King's College London,

King's College London School of Medicine, Weston Education Centre, London, UK.

Personal non-commercial use only. The Journal of Rheumatology Copyright @ 2015 . All rights reserved. 
Address correspondence to Professor D.L. Scott, Weston Education Centre, King's College London, 10 Cutcombe Road, London SE5 9RS, UK. E-mail: d.scott1@nhs.net

James Galloway has received grant support from Pfizer; and consulted for Merck Sharpe and Dome, Roche Products Limited, and Pfizer. David L. Scott is supported by the National Institute for Health Research Programme Grants For Applied Research, RP-PG-0610-10066; receives grant support from Arthritis Research UK and Pfizer; and has consulted for Roche Products Limited, Napp Pharmaceuticals, and Bristol-Myers Squibb Pharmaceuticals Ltd.

\section{REFERENCES}

1. Pope J, Thorne J, Haraoui B, Karsh J, Keystone E. Arthritis clinical trials at a crossroad. J Rheumatol 2015;42:14-7.

2. Collier R. Legumes, lemons and streptomycin: a short history of the clinical trial. CMAJ 2009;180:23-4.

3. Scott DL, Wolfe F, Huizinga TW. Rheumatoid arthritis. Lancet 2010;376:1094-108.

4. van Nies JA, Krabben A, Schoones JW, Huizinga TW, Kloppenburg M, van der Helm-van Mil AH. What is the evidence for the presence of a therapeutic window of opportunity in rheumatoid arthritis? A systematic literature review. Ann Rheum Dis 2014;73:861-70.

5. O'Dell JR, Mikuls TR, Taylor TH, Ahluwalia V, Brophy M, Warren $\mathrm{SR}$, et al. Therapies for active rheumatoid arthritis after methotrexate failure. N Engl J Med 2013;369:307-18.

6. Ma MH, Scott IC, Kingsley GH, Scott DL. Remission in early rheumatoid arthritis. J Rheumatol 2010;37:1444-53.

7. van der Velde G, Pham B, Machado M, Ieraci L, Witteman W, Bombardier C, et al. Cost-effectiveness of biologic response modifiers compared to disease-modifying antirheumatic drugs for rheumatoid arthritis: a systematic review. Arthritis Care Res 2011;63:65-78.

8. Sokka T, Pincus T. Most patients receiving routine care for rheumatoid arthritis in 2001 did not meet inclusion criteria for most recent clinical trials or American College of Rheumatology criteria for remission. J Rheumatol 2003;30:1138-46.

9. McBurney CA, Vina ER. Racial and ethnic disparities in rheumatoid arthritis. Curr Rheumatol Rep 2012;14:463-71.

10. Harrison MJ, Tricker KJ, Davies L, Hassell A, Dawes P, Scott DL, et al. The relationship between social deprivation, disease outcome measures, and response to treatment in patients with stable, long-standing rheumatoid arthritis. J Rheumatol 2005;32:2330-6.

11. Graves H, Scott DL, Lempp H, Weinman J. Illness beliefs predict disability in rheumatoid arthritis. J Psychosom Res 2009;67:417-23.

12. Dixon WG, Hyrich KL, Watson KD, Lunt M, Galloway J, Ustianowski A, et al. Drug-specific risk of tuberculosis in patients with rheumatoid arthritis treated with anti-TNF therapy: results from the British Society for Rheumatology Biologics Register. Ann Rheum Dis 2010;69:522-8.

13. Dumville JC, Watson J, Raynor P, Torgerson DJ. Research governance: a barrier to ethical research? QJM 2004;97:113-4.

14. Ashcroft RE, Newson AJ, Benn PM. Reforming research ethics committees. BMJ 2005;331:587-8.

15. Tanimoto T, Kami M, Shibuya K. Research misconduct and scientific integrity: a call for a global forum. Lancet 2013;382:940.

J Rheumatol 2015;42:18-20; doi:10.3899/jrheum.141270 